\title{
Self-efficacy and Self-esteem in Relationship with Mindfulness in Psychiatric Patients, A Descriptive Study
}

Fateh Sohrabi ${ }^{1}$, Fayegh Yousefi ${ }^{2}$

1. Ph.D. Candidate of Clinical Psychology, Shahid Beheshti University of Medical Sciences, Tehran, Iran. ORCID ID: 00000002-0159-8273.

2. Associate Professor, Spiritual Health Research Center, Research Institute for Health Development, Kurdistan University of Medical Sciences, Sanandaj, Iran., (Corresponding Author), Tel: +98-9186456599, Email: fykmsu@gmail.com. ORCID ID: 0000-0001-5503-3326.

\begin{abstract}
Background and Aim: Past studies have showed that self-esteem (SES) and self-efficacy (SEF) have a positive and significant relationship with improvement of the patients. On the other hand, it has been proved that mindfulness improves the patient's health. Yet, the relationships between these three variables have not been investigated enough. The aim of this study was to investigate the relationship of mindfulness with SES and SEF in the patients with severe psychological problems.

Materials and Methods: This analytic-descriptive study included all eligible patients. After informed consent (213 participants), necessary data were collected and we used Cognitive and Affective Mindfulness Scale- Revised (CAMS-R), Rosenberg's Self-Esteem Scale, Mindfulness-based Self-Efficacy Scale-Revised (MSES-R) in this study. Using the 20th version of SPSS software, data were analyzed by descriptive statistics, Pearson's coloration coefficient, independent t-test, and simple linear regression.

Results: Among 213 patients, 151 were male (\%70/7), and 62 were female (\%29/3). Mean age of the participants were $32 \pm 10 / 04$. Linear Regression showed a positive and significant relationship between variables (mindfulness with SES $r=.489$, mindfulness with SEF $r=.307$. Also, we found that we could predict a significant alteration in mindfulness by self-efficacy and self-esteem.

Conclusion: It seems that mindfulness has a reciprocal relationship with SEF and SES which can have influence on the effects of each other. It is likely that SES and SEF are among the factors which are associated with the effectiveness of the mindfulness-based therapies.
\end{abstract}

Keywords: Mindfulness, Self-esteem, Self-efficacy, Psychiatric Patients

Received: Apr 28, 2019

Accepted: Sep 27, 2020

How to cite the article: Fateh Sohrabi, Fayegh Yousefi. Self-efficacy and Self-esteem in Relationship with Mindfulness in Psychiatric Patients, A Descriptive Study. SJKU. 2020;26(4):103-113.

Copyright (C) 2018 the Author (s). Published by Kurdistan University of Medical Sciences. This is an open access article distributed under the terms of the Creative Commons Attribution-Non-Commercial License 4.0 (CCBYNC), where it is permissible to download, share, remix, transform, and buildup the work provided it is properly cited. The work cannot be used commercially without permission from the journal 


\title{
خودكار آمدى و عزتنقس و رابطه آنها با ذهن آكاهى در بيماران روانبزشكى، يك مطالعه توصيفى
}

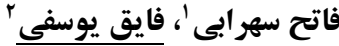

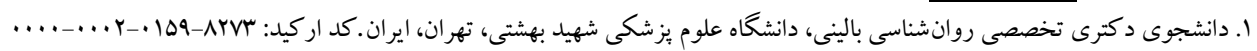

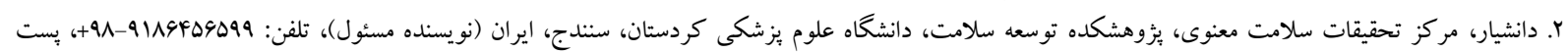

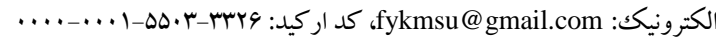

جكيله زمينه و هدف: مطالعات نشان دادهاند كه خود كار آمدى و عزت نفس ارتباط معنى دار و مثبتى با وضعيت بهبودى بيماران دارند. از

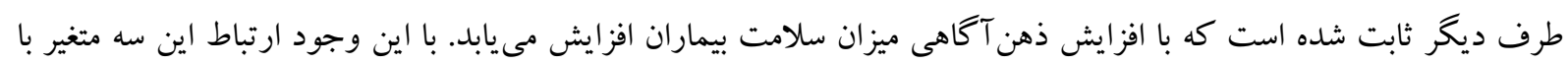

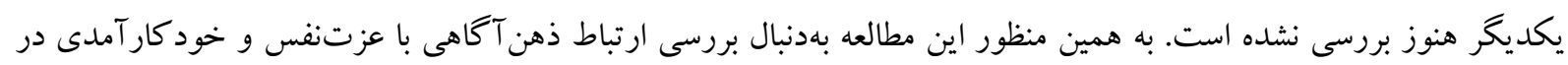
بيماران با مشكلات شديد روانشناختى است.

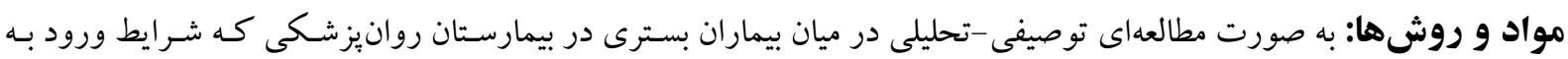

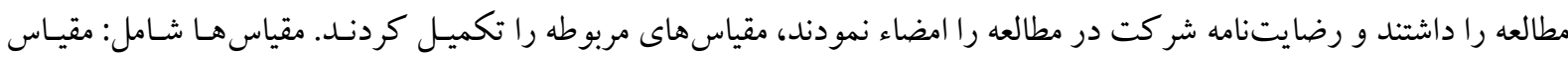

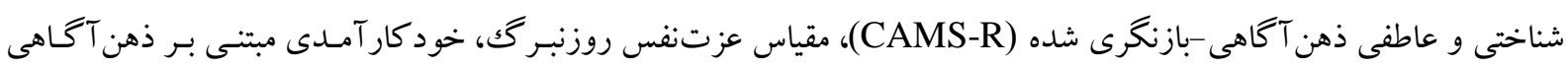

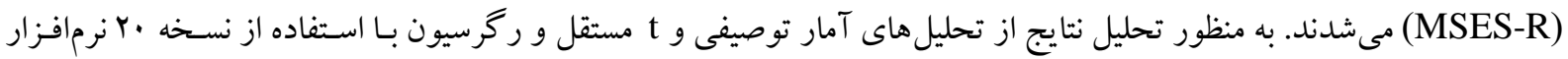
SPSS

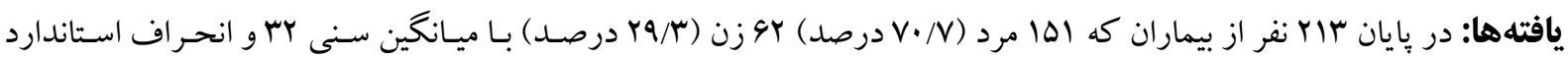

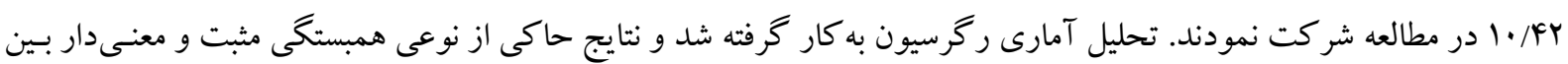

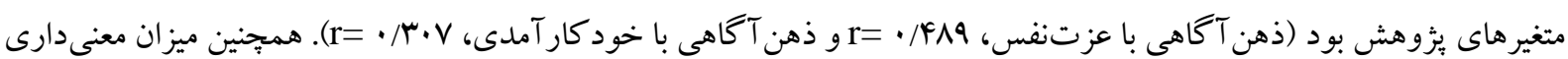

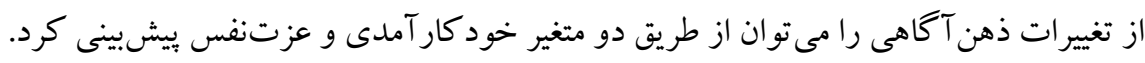

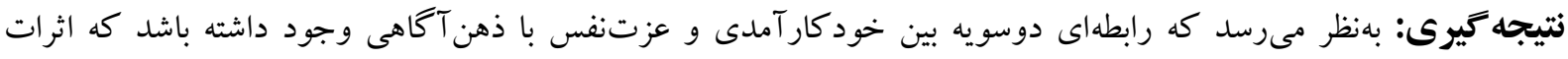

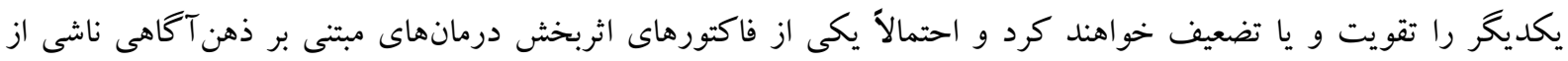
بهبودى در حيطههاى خود كار آمدى و عزت بنفس است.

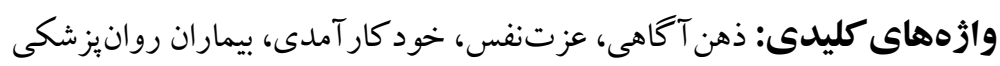
وصول مقاله:ه//T/N اصلاحيه نهايى:99/V/0 يذيرش:99/V/9 
شخصيت آدمى به شمار مى آيد و بر خيلى از اعمال وى

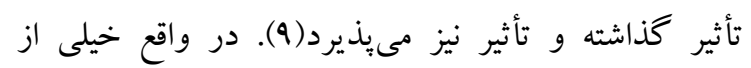
بيماران روانيزشكى به خاطر ماهيت بيمارى و همين طور

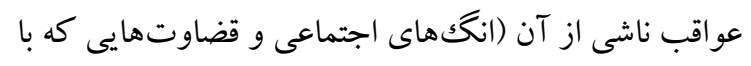

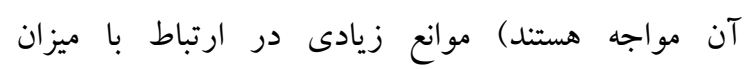

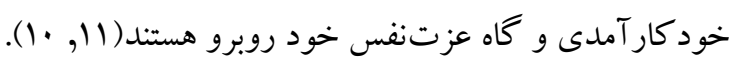
ذهن Tكاهى يكى از راههايى است كه براى افز ايش اعتماد به نفس و كاهش اضطراب اجتماعى بيشنهاد شده است( I I I).

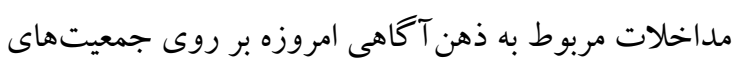

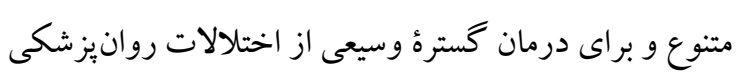

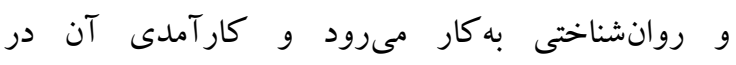
جمعيتهاى مختلفى بر اساس تحقيقات به اثبات رسيده

است(سו, 9).

ذهن Tكاهى مفهومى است كه اخيراً وارد حيطه روان درمانى

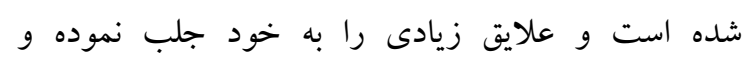

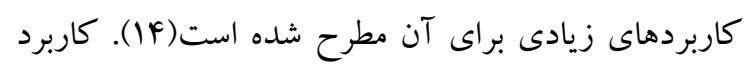

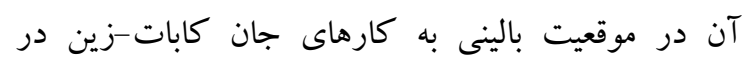

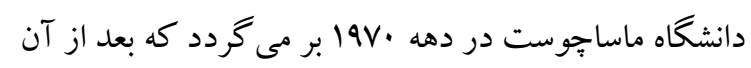

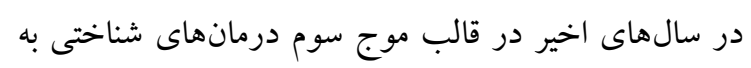

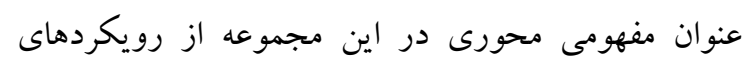

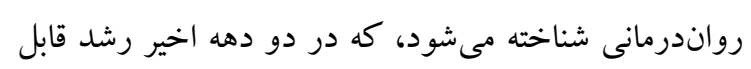

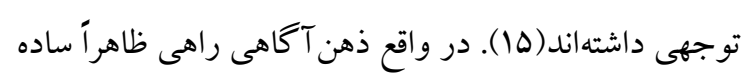

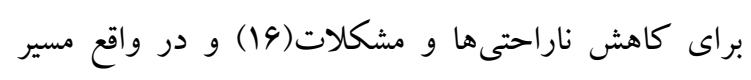

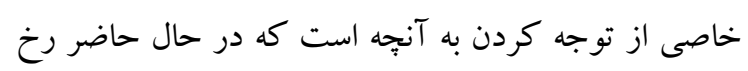

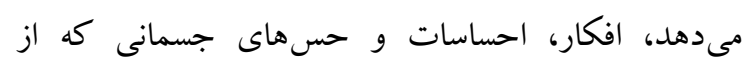

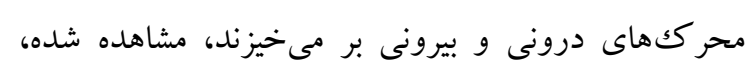

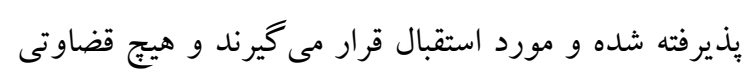

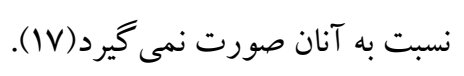

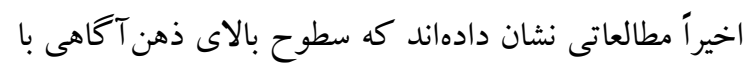

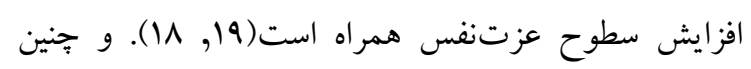
عنوان كردهاند كه عزتنفس نقش واسطهاى و تعديل كننده

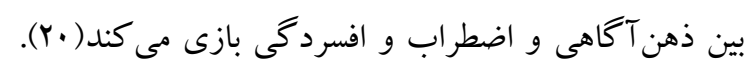

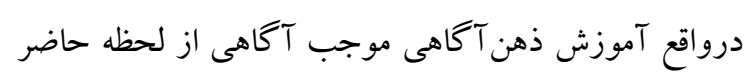

مقدمه خودكار آمدى و عزتهن عنفس از متغيرهاى روانشناختى

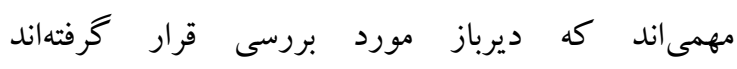
خودكارآمدى به باورهايى اطلاق مىشود كه تأثيرات

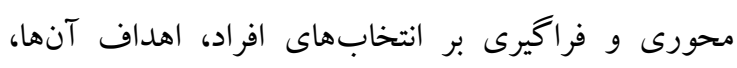

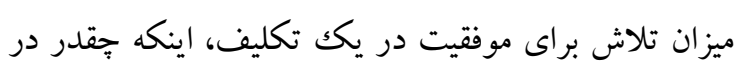
مواجهه با شكست بر روى يكك تكليف بافشارى مى كنند،

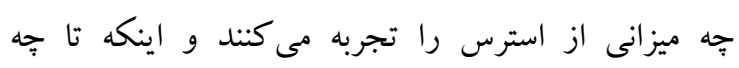

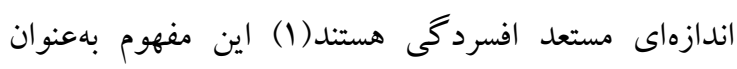
مفهوم محورى نظريه اجتماعى و شناختى بندورا نيز شناخته شده و يكى از مهمترين فاكتورهاى انكيزشى به شمار

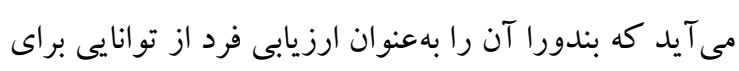

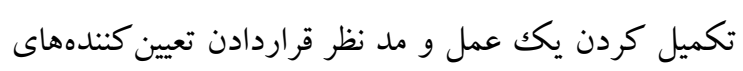

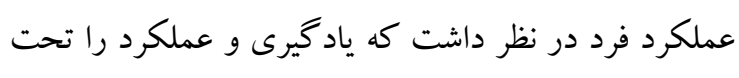

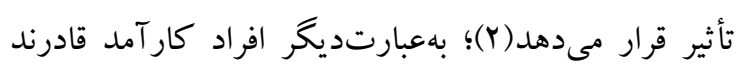

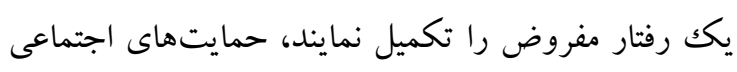

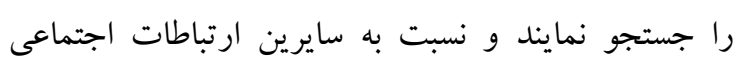

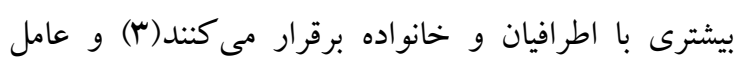
مهمى در موفقيت اجتماعى و شغلى است(F). بر بر اساس ونس

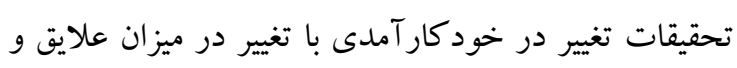

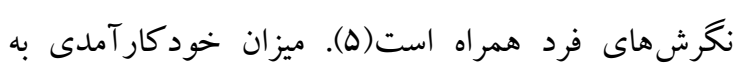

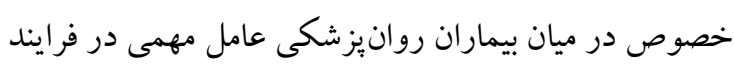

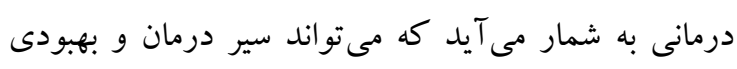
فرد را به نحو مؤثرى تحت تأثير قرار دهد.

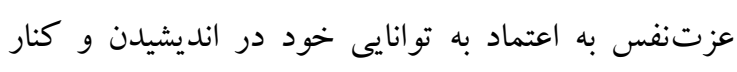
آمدن و درواقع احساس ارزشمند بودن و شايسته بودن بون اطلاق مى شود كه به نوعى احساس دوست داشتن خود كفته

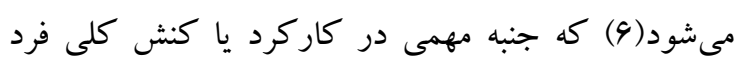

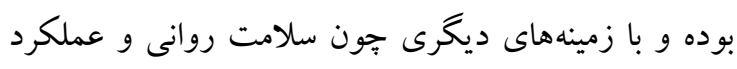

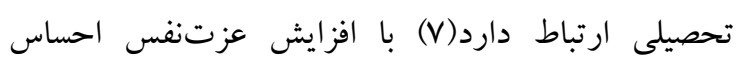

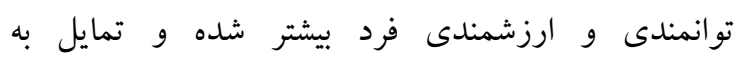
برخوردارى از سلامت بالاتر و برتر در فرد به وجندي

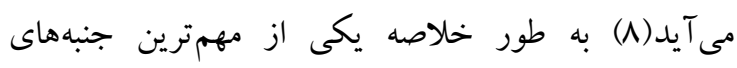




\section{مواد و روشها}

اين مطالعه به صورت يكك مطالعه توصيفى مقطعى به دنبال بررسى رابطة بين ذهن آكاهى با عزتنفس و خود كار آمدى

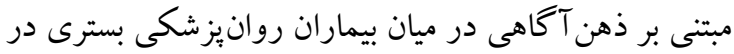

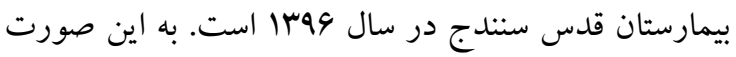
از ميان تمامى بيماران بسترى در بخشهاى مختلف

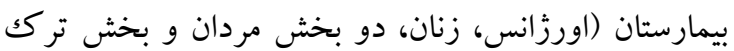
اعتياد) آنهايى كه علائم روانيزشكىشان تثبيت شده و توانايى خواندن و نوشتن در سطح اول راهنمايى را به منظور درك گويههاى آزمون را داشتند در صورت رضايت شخصى بعد از اخذ اطلاعات لازم مقياسهاى مورد نياز را

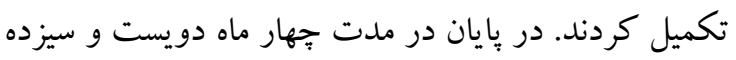

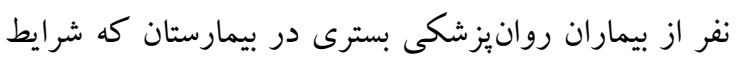
ورود به تحقيق را داشتند به مقياسهاى آزمون ياسخ دادند. بعد از تكميل برسشنامها، دادههاى بهدست آمده وارد نسخه r برم افزار SPSS شده و مورد تجزيه و تحليل آمارى قرار كرفت. مقياس خود كار آمدى مبتنى بر ذهن آكاهى (MSES): يك

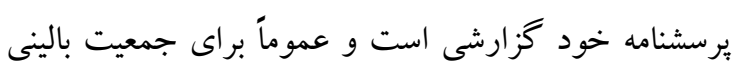

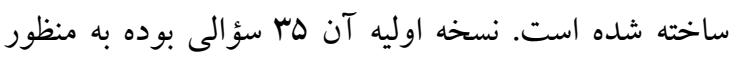

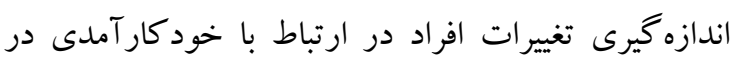

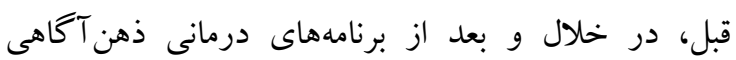

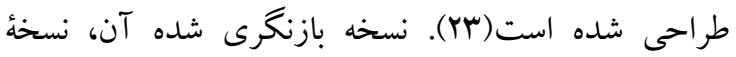
كو تاهترى با ب سؤال است كه دادههاى اوليه به دست آمده از آن حاكى از ويز گیىهاى مناسب روانسنجى آن است و و

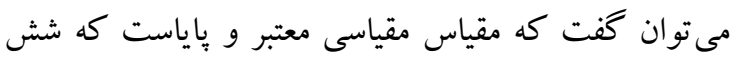
خرده مقياس را داراست(YF). با توجه به نتايج مطالعه مربوط به خصوصيات روانسنجى آزمون مذكور مىتوان كفت كه:

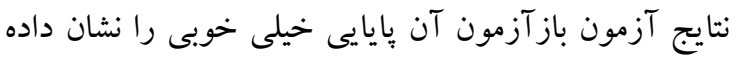

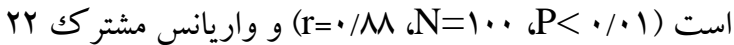
مقياس آن V^٪ است، ثبات درونى آن خيلى بالاست (آلفاى كرونباخ= \$4/•)، رابطه معكوس خوبى با نسخه كوتاه
شده و فرد را براى ياسخ انطباقى و ساز كارانه آماده مى كند

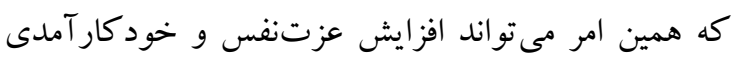

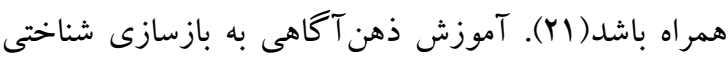
منجر خواهد شد كه منجر به تغيير رفتارى مؤثرى خواهد شد كه به كاهش تكانش گرى و افزايش رفتار ساز كارانه منجر خواهد شد و از آن به عنوان تكليف مؤثرى براى كسانى كه رفتارهاى مخرب دارند، افسردهاند، كسانى كه مشكلات

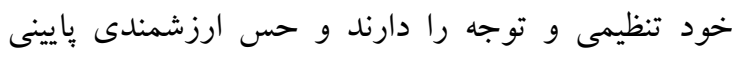
دارند و همين طور كسانى كه نغرانى ها، خاطرات و خ خلقيات منفى دارند ياد مى كنند(Y) (Y)

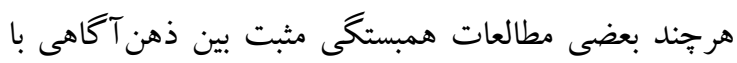

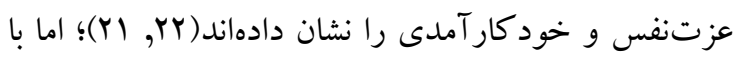
اين وجود به مطالعات بيشترى براى مشخص شدن ارتباط اين

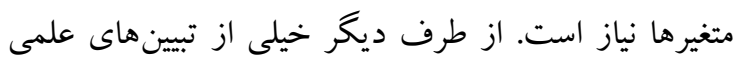

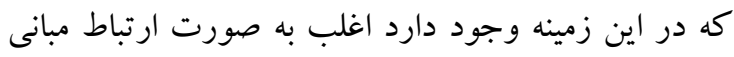
نظرى و تئورى زيربنايى متغيرهاى مذكور بيان شده است كه براى وضوح آنها به مطالعات تجربى نياز است. همبنين در جمعيتهاى روانيزشكى و افرادى كه نياز به مداخلات دارويى و مراقبتهاى ويزه روانيزشكى دارند جنين مطالعهاى انجام نشده است. از اين روى، مطالعه حاضر نه بر

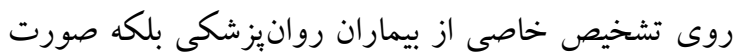
كلى روى گروههاى تشخيصى بيماران با مشكلات شديد روانشناختى انجام شد و به دنبال بررسى ارتباط بين ذهن آكاهى با خود كار آمدى و عزتنفس بيمارانى است كه در بيمارستان روانيزشكى بسترى بوده و تحت مداخلات

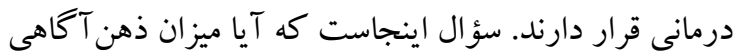
با عزتنفس بيماران مىتواند ارتباط داشته باشد، در مورد خودكار آمدى آنان جطور، آيا مى تواند به موزات افزايش ميزان ذهن آكاهى افراد، عزتنفس و يا خود كار آمدى آنان

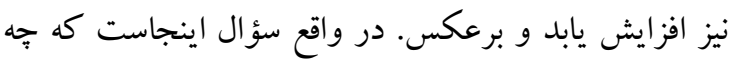

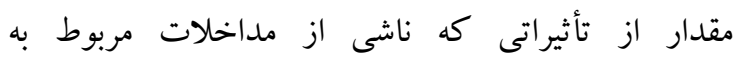
ذهن آكاهى به وجود مى آيد را مىتوان در متغير هايى مانند عزتنفس و خود كار آمدى جستجو كرد. 
مقياس عزتنفس روزنبرك؛: اين مقياس در سال 1990

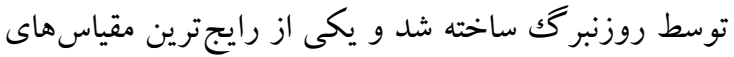

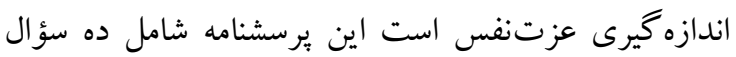

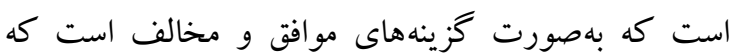

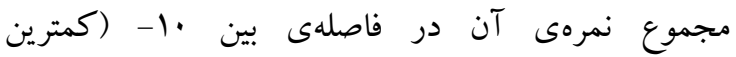
عزتنفس) و · +(بيشترين عزتنفس) است. اين مقياس، عزتنفس كلى و ارزش شخصى را اندازه مى گيرد و نسخه

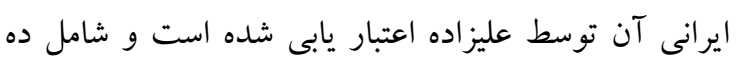

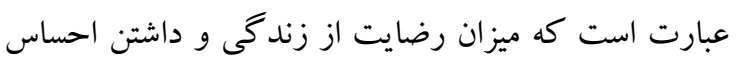
خوب در مورد خود را مىسنجد. ضريب آلفاى كرونباخ براى اين مقياس در دامنه NV/ تا MN/ • قرار دارد، همجنين

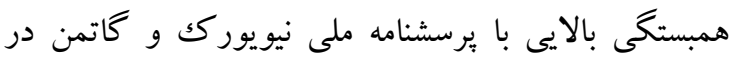
سنجش عزتنفس به دست داده است(YV).

\section{يافته ها} در مجموع rاب نفر در مطالعه حاضر شركت كردند و

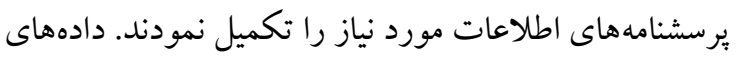

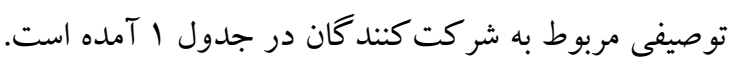

مقياس اضطراب، افسردگى و استرس و همجنين اعتبار افتراقى مناسبى را نشان داد و اعتبار همخراى مناسبى با فئ مقياسهاى اندازهيرى ذهن آكاهى نشان داده است (مانند IMS, FFMQ, FMI, MAAS فارسى اين مقياس بايايى آزمون-بازآزمون مناسب و و

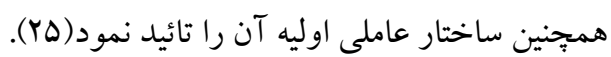

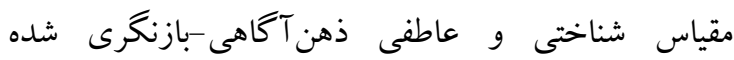
(CAMS-R)

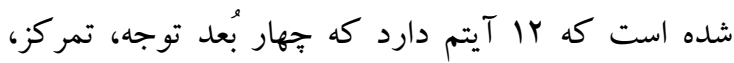
آكاهى و بذيرش را در طى فعاليتهاى روزانه تشكيل شده

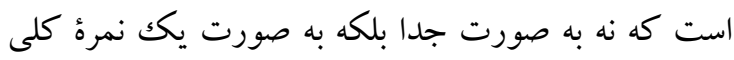
ذهن آكاهى محاسبه مىشوند. اين مقياس آلفاى كرونباخ

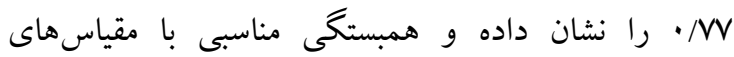

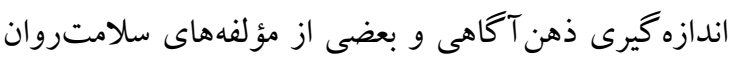
ماند آرامش ذهنى، انعطاف شناختى، تنظيم هيجانى و إنى نشان داده است، ضريب آلفاى كرونباخ نسخه فارسى آن آن

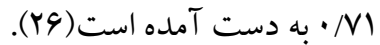

\begin{tabular}{|c|c|c|c|c|c|}
\hline \multirow[t]{2}{*}{$\%$} & \multirow[t]{2}{*}{$\mathbf{N}$} & \multirow{2}{*}{$\begin{array}{l}\text { M } \\
r r\end{array}$} & \multirow{2}{*}{$\frac{\text { SD }}{1 \cdot / F r}$} & \multicolumn{2}{|c|}{ متغيرهاى جمعيت شناختى } \\
\hline & & & & & 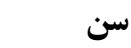 \\
\hline$r q / r$ & 194 & & & 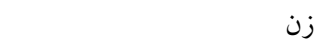 & جنس \\
\hline$V \cdot / V$ & 101 & & & مرد & \\
\hline f. & $\wedge \Delta$ & & & ابتدايى و راهنمايى & تحصيلات \\
\hline f. & $\wedge \Delta$ & & & متو سطه & \\
\hline$r$ r. & Fr & & & دانشگاهى & \\
\hline is & $1 . r$ & & & بيكار & 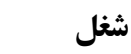 \\
\hline fo & 99 & & & ياره وقت و آزاد & \\
\hline$\Delta$ & 1. & & & شاغل & \\
\hline r & $\Delta$ & & & ساير (بازنشسته و دانشجو و ...) & \\
\hline
\end{tabular}

بىاختيارى، اختلال افسردگى اساسى، اختلال تبديلى، اختلال شخصيت و اختلالات طبقه سوءمصرف مواد.
شر كت كنند كان گروه نمونه هفت تشخيص روانيزشكى را داشتند مانند اسكيزوفرنيا، اختلال دو قطبى، وسواس 
نتايج مربوط به آمارهاى توصيفى (ميانگين، انحراف استاندارد و كمترين و بيشترين مقدار) سه متغير مورديزوهش

جدول r. ميانكين و انحراف استاندارد با بيشترين و كمترين نمره مربوطه در متغيرهاى مورد مطالعه

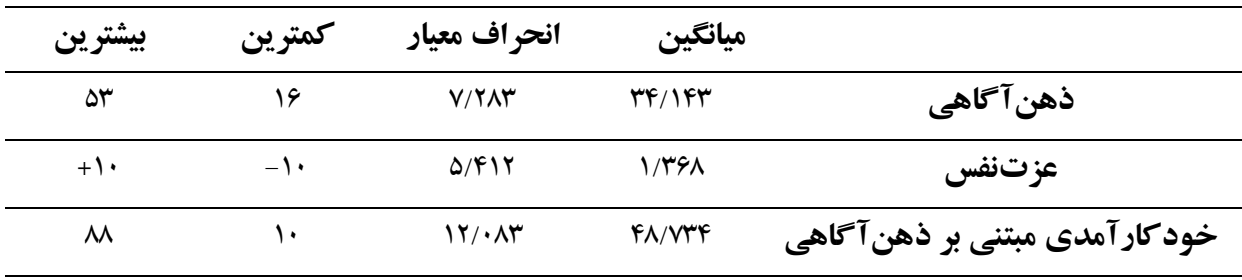

معنى

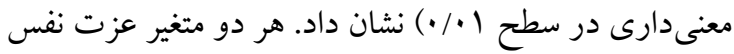
و خودكارآمدى نيز همبستخى مثبت و معنىدارى نشان دادند.
همجنين نتايج مربوط به آزمون همبستگى بيرسون در سه

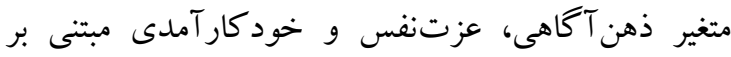

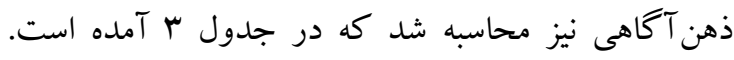

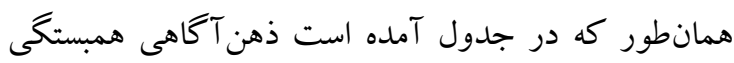

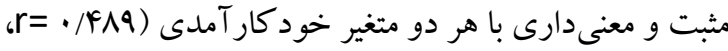

جدول r. نتايج ماتريس همبستكى بيرسون براى سه متغير يزوهش و ابعاد مربوط به يرسشنامه خود كار آمدى مبتنى بر ذهن آكاهى ذهن آكاهى

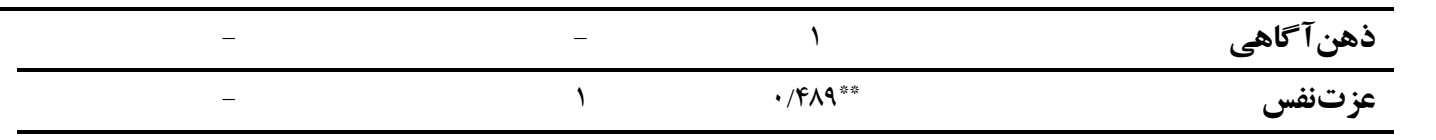

\begin{tabular}{|c|c|c|c|}
\hline 1 & $\cdot / \mu r \cdot * * * * *$ & $\cdot / r \cdot V^{\text {絭 }}$ & خود كار آمدى مبتنى بر ذهن آ كاهى \\
\hline$\cdot / 4 \pi \mu^{* * * * * *}$ & $\cdot /$ Y $11^{* * * *}$ & $\cdot / q \cdot 1^{* * * * *}$ & تنظيم هيجانى \\
\hline$\cdot / \Gamma \vee q^{* * * * *}$ &.$/ 191 *$ & $\cdot / \kappa \cdot \Lambda^{* * * *}$ & متاذت \\
\hline
\end{tabular}

\begin{tabular}{|c|c|c|c|}
\hline$\cdot / \Lambda 9^{* * * *}$ & $\cdot / \Lambda^{* * * * *}$ & $\cdot / Y Y Q^{* * * *}$ & مهارتهاى اجتماعى \\
\hline$\cdot /\left.r\right|^{* * * * *}$ & $\cdot / \mu^{* *}$ & $\cdot / 19 \Lambda^{* * * *}$ & تحمل فشار \\
\hline$\cdot / 191^{* * * *}$ & $\cdot / \mu \Lambda^{* * * * *}$ & $\cdot / l F F^{*}$ & مسئوليت يذيرى \\
\hline$\cdot /\left.Y 9\right|^{* * * * * *}$ & $\cdot / \mu \mathrm{V}^{* * * * *}$ &.$/ 1 F \Lambda^{*}$ & كارايى بين فردى \\
\hline
\end{tabular}

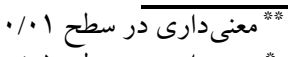

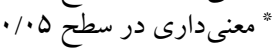

نتايج تحليل رگرسيون خطى براى بررسى ارتباط بين متغيرها

ابعاد يرسشنامه خودكارآمدى مبتنى بر ذهن آكاهى در در جدول F آمده است.

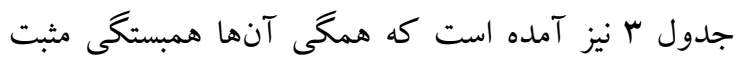
معنى ارى به نمره كل برسشنامه و همجنين عزتنفس و

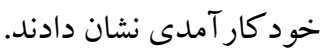




\begin{tabular}{|c|c|c|c|c|c|c|}
\hline Sig. & $\mathbf{t}$ & ضريب بتا & $\mathbf{R}^{2}$ & $\mathbf{R}$ & شاخصها & متغير ملاكى \\
\hline$\cdot / \cdot \cdot 1$ & $\Lambda / \cdot \Delta \Lambda$ & $\cdot / 4 \wedge 9$ & . & $\cdot / 4 \wedge 9$ & عزتنفس & \\
\hline.$/ .1$ & . /AG & $\cdot / r \cdot V$ & .1 .94 & $\cdot / \mu \cdot V$ & خود كار آمدى & \\
\hline
\end{tabular}

زمينهاى براى مقايسه كارآمدى درمانهاى مختلف تمييز اثرات درمانى آنها را فراهم نمايد. از طرف ديخر همخوان با اين نتايج مطالعات ديخرى كه به صورت كار آزمايى بالينى انجام شدهاند نتايجى از كار آمدى مناسبى را براى اثربخشى ذهن آكاهى عنوان كردهاند. براى مثال مطالعهاى نشان داد كه آموزش ذهن آكاهى در افرادى كه مصرف كننده سيگار بودند با اضطراب كمتر اين افراد، مشكلات كمتر در تمركز، وسوسه و وابستكى كمتر و همجنين كارآمدى بيشتر براى مديريت علائم مربوط به مصرف سيگار همراه بود(سM). در مطالعه ديخرى نيز ذهن آكاهى با افزايش در ميزان خودكارآمدى همراه بود(MF). زمانى كه به بيماران ديابتى آموزش ذهن آكاهى دريافت داشتند مديريت بيشترى بروى علائم خود داشتند(ها). در يكك فرا تحليلى كه اثربخشى درمانهاى مبتنى بر ذهن آكاهى را در جمعيت بيماران روانيزشكى مورد مطالعه قرار داده است عنوان مى كنند كه درمانهاى مبتنى بر ذهن آكاهى را درمانى مؤثر در اين زمينه قلمداد

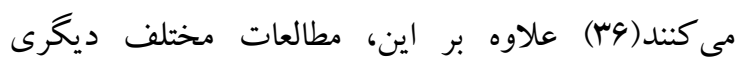
كاركرد ذهن آكاهى را بر روى جميعت هاى روانيزشكى

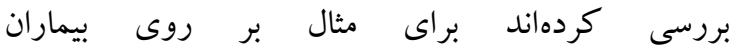
اسكيزوفرنيك(rV)، اضطر اب و افسردگى، اختلالات مربوط لرك به سوء مصرف مواد(M)، يا علائم مربوط به استرس يس از از آسيب(Mو). اگرجهه مطالعات فوق اغلب از نوع مداخلهاى

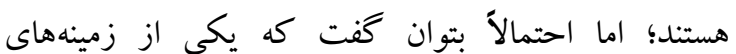
كار آمدى درمانهاى مبتنى بر ذهن آكاهى تأثيرى است كه بر مؤلفهايى از قبيل خود كار آمدى و عزتنفس اين بيماران مى گذارند. اين مورد مىتواند براى مطالعات آتى مورد

$$
\text { بررسى بيشترى قرار بخيرد. }
$$

همانطور كه مشاهده مىشود ميزان عزتنفس و خود كار آمدى به ترتيب مى تو انند سץ درصد و 9 درصد از يراكندگى مربوط به ذهن آكاهى را ييشبينى كنند؛ بنابراين مى توان كفت كه هر دو متغير خود كار آمدى و عزتنفس به صورت معنىدار و مشخصى مىتواند ميزانى از تغييرات

$$
\text { ذهن آكاهى را تبيين نمايند. }
$$

نتايج مطالعه نشان داد كه ذهن آكاهى همبستكى مثبتى با عزتنفس و خود كار آمدى در بيماران روانيزشكى دارد. به اين صورت كه به موازات افزايش ميزان ذهن آكاهى بيماران خود كارآمدى بيماران و همجينين ميزان عزتنفس آنان

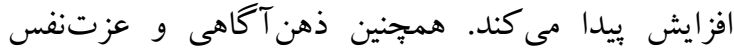
همبستكى مثتى با تمامى ابعاد خودكار آمدى مبتنى بر ذهن آكاهى نشان دادند. در زمينه ارتباط مثبت و معنىدار ذهن آكًاهى و عزت نفس با بزٔوهشهاى اسكندر و همكاران

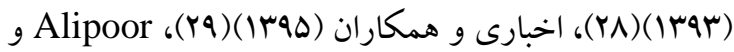
همكاران (Y.IV)(Y.(Y)، همخوان است. در زمينه ارتباط خود كار آمدى و ذهن آكاهى نيز تحقيقاتى كه انجام شده است. نتايج مثبت و معنىدارى را بهدست آورده اند براى مثال مى توان به مطالعه رستمى و همكاران (سوسו)(Iآ)،

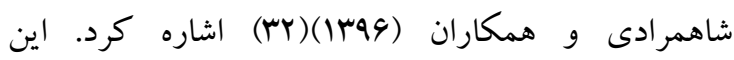
همخوانىها نشان مىدهد كه دو متغير مذكور ارتباط مشخصى با ذهن آكاهى دارند و مىتوان براى بررسى كار آمدى مطالعات مبتنى بر ذهن آكاهى به عنوان نتيجه درمانى مورد توجه قرار گيرند جون به ميزان مناسبى تغييرات آن را در خود نشان مىدهند. بررسى اين متغيرها مىتواند 


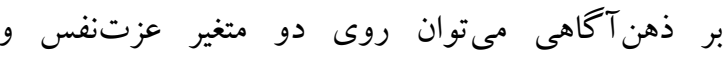
خود كار آمدى بررسىهاى بيشترى انجام داد كه مى توان دوى دوند اطلاعات مفيدى براى برّوهشخران و همينطور درمانكران

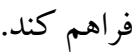

\section{نتيجه كيرى}

نتايج نشان داد كه خود كار آمدى و عزت تنفس مفاهيم مهمى و محورى هستند و ارتباط مشخص و معنىدارى با ساب ذهن آكاهى دارند. از آنجايى كه ذهن آكاهى امروزه يكى از

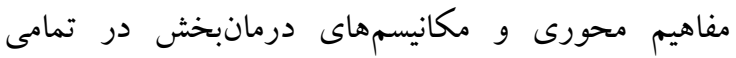
درمانهاى روانشناختى به شمار مى آيد در افزايش و كاهش دهر تأثيرات آن دو متغير عزت نفس و خود كار آمدى نئن نيز مؤثرند. جرا كه از لحاظ تئورى با افزايش ذهن آكاهى تونى توانايى بودن

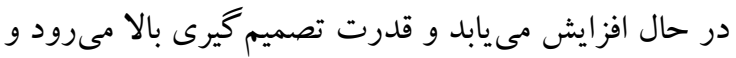

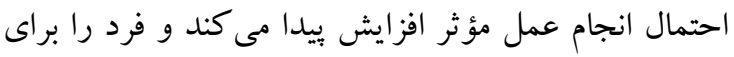

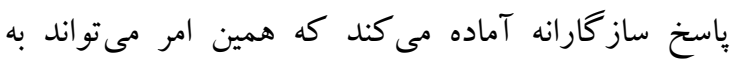

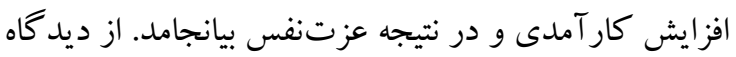

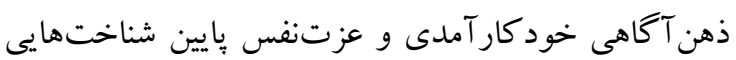

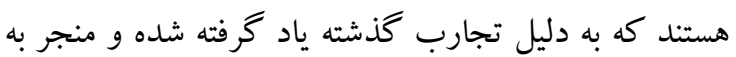
عمل مىشوند و در طول زمان با احساسات فرد ارتباط بيدا كرده و خودكار شده و به عادت تبديل شدهاند و در اينجا نوعى التزام شناختى نارس ايجاد مىشود كه فرد اين

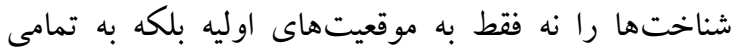
موقعيتها تعميم مىدهد. ذهن آكاهى در ابتدا اين جرخهُ

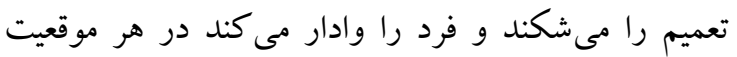
بدون قضاوت، متناسب با درخواستهاى آن موقعيت رفتار كند، يعنى همان مؤلفه اصلى ذهن آكاهى تحت عنوان بودن در حال حاضر كه با مؤلفه فراغت از قضاوت و واكنش همراه مىشود. جِين كارى موجب گسست از التزامات شناختى نارس كذشته مىشود و فرد توانايى احساس مسئوليت و همينطور قدرت انتخاب خواهد داشت كه نتيجأ

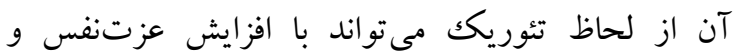
خو د كار آمدى همر اه و همگام باشد.
علاوه بر اين موارد غير از جمعيت بالينى، شواهد معتبرى

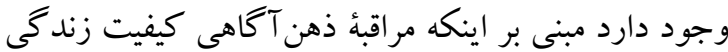
مربوط به سلامت را بهبود مىبخشد، به حفظ سلولهاى مغزى كه بهطور طبيعى همراه با افزايش سن تحليل مىروند كمكك مى كند، درد مزمن را كاهش داده و كيفيت خواب را بهبود مىبخشد، حافظه و توانيىهاى ذهنى را بهتر

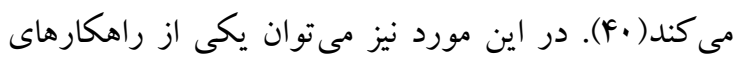
جنين اثراتى را در متغيرهايى مانند عزتنفس و و خود كار آمدى افزايش يافته آنان جستجو كرد. نتايج مطالعه

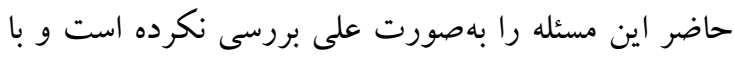
توجه به محدوديتهاى مربوطه و ماهيت مطالعه، بايد با ليا

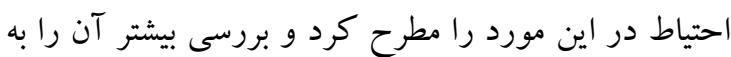
مطالعات آتى واكذار كرد. هر مطالعهاى محدوديتهاى خاصى دارد و مطالعه حاضر نيز

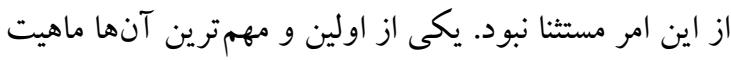

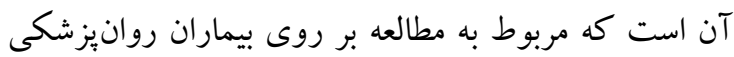
است كه محدوديتهاى خاصى به همر اه دارد. جون بالطبع اين بيماران تا زمان تثبيت علائم روانيز شكى قادر به انجام تكاليف شناختى كه براى مطالعات علمى از اين دست ضرورى است نيستند و همين امر ميزان افراد مورد مطالعه يعنى كروه نمونه را خيلى كاهش مىدهد؛ كه اين خود نيز يكى از محدوديتهاى ديخر مطالعه است، به همين دليل ييشنهاد مى شود كه مطالعه بروى جمعيتهاى بزركت تر انجام

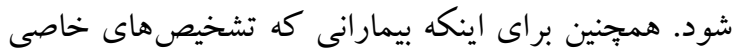
دارند را در قالب اين ابعاد شناخت، تفكيك خروههاى تشخيصى مى تواند گزينه مناسبى باشد كه بالطبع تبيينهاى خاص و سودمندى در برخواهد داشت؛ بنابراين توصيه مىشود كه براى مطالعات آتى گروههاى جداكانهاى از بران

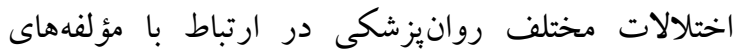
مذكور مورد مطالعه قرار كيرند. اين جنين مىتوان دلالتهاى بيشترى در اين مورد بهدست آورد كه در زمينه

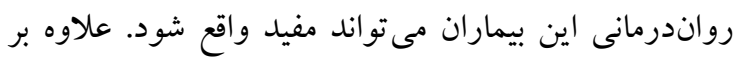

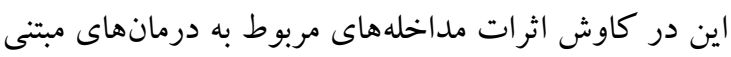




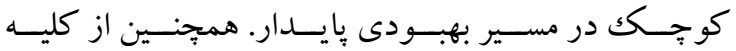

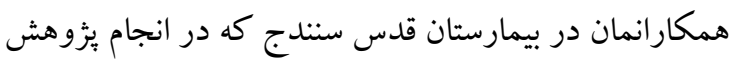

$$
\begin{aligned}
& \text { ما را يارى كردند سباسگز اريم. }
\end{aligned}
$$

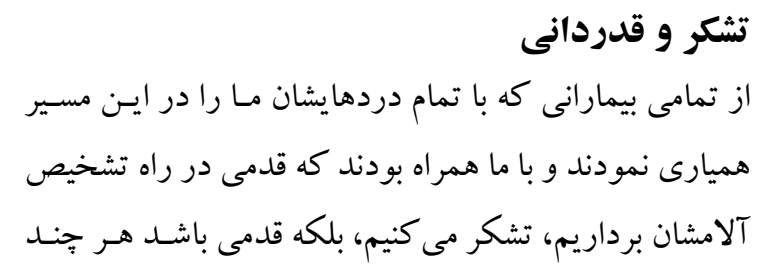

$$
\begin{aligned}
& \text { منابع }
\end{aligned}
$$

1.Bandura A. Self-efficacy: Toward a Unifying Theory of Behavioral Change. Psychol Rev. 1977;84(2):191 -215.

2.Eccles JS, Wigfield A. Motivational beliefs, values, and goals. Annu Rev Psychol. 2002; 53(1):109-32.

3.Schwarzer R, Luszczynska A. Health behavior constructs: Theory, measurement, and research. IMGKD, editor. Self-Efficacy:. National Cancer Institute. 2007.

4.Iroegbu MN. Self-Efficacy and Work Performance: A Theoretical Framework of Albert Bandura's Model, Review of Findings, Implications, and Directions for Future Research. Intl J Phys Beh Res. 2015;4(4): 170-3.

5.Niemivirta M, Tapola A. Self-efficacy, interest, and task performance: Within-task changes, mutual relationships, and predictive effects. Z PADAGOG PSYCHOL. 2007;21(3/4):241-50.

6.Mruk CJ. Self-esteem research, theory, and practice: Toward a positive psychology of selfesteem. Springer Publishing Company; 2006 May 9.

7.Sharafi L, Taghibaygi M, Alibaygi A. The Impact of Self-Esteem and Personal Characteristics on Educational Improvement of Razi University Agriculture Students. J Agric Educ. 2015;32:113-22.

8.Mann MM, Hosman CM, Schaalma HP, De Vries NK. Self-esteem in a broad-spectrum approach for mental health promotion. Health Educ Res. 2004;19(4): 357-72.

9.Ghaffari F, Fotokian Z, Mazloom SR. Effect of group exercise program on self-esteem of nursing students. J Babol Univ Medical Sci. 2006; 9(1):25-57.

10.Sohrabi F, Esfandyari G, Yousefi F, Abdollahi N, Saed G, Bakhivushi S. The relationships between self-esteem, demographic variables, psychiatric diagnosis and Frequency of hospitalization with mental illness stigma in psychiatric patients. Shenakht journal of psychology \& psychiatry. $2016 ; 3(4): 27-38$.

11.Sohrabi f, saed g, Abdollahi N, Ramezani G. The Relationship with Suicidal Thought and Stigma and Self-esteem in Psychiatric Patients. Int J Nurs Educ. 2019;7(3):48-54.

12.Apaolaza V, Hartmann P, D'Souza C, Gilsanz A. Mindfulness, Compulsive Mobile Social Media Use, and Derived Stress: The Mediating Roles of Self-Esteem and Social Anxiety. Cyberpsychol Behav Soc Netw. 2019;22(6):388-96.

13.Kocovski NL, Segal ZV, Battista S R. Mindfulness and psychopathology: Problem formulation. Clinical Handbook of Mindfulness: Springer; 2009.

14.Goyal M, Singh S, Sibinga EM, Gould NF, Rowland-Seymour A, Sharma R, et al. Meditation programs for psychological stress and well-being: a systematic review and metaanalysis. JAMA Intern Med. 2014;174(3):357-68.

15.Ost L-G. Efficacy of the third wave of behavioral therapies: a systematic review and metaanalysis. Behav Res Ther. 2008;46:296-321.

16.Germer K, Siegel R, Fulton P. Mindfulness and Psychotherapy. New York: The Guilford Press; 2005. 
17.Vicki SC. The Power of Being Present: The Value of Mindfulness Interventions in Improving Health and Well-Being. West J Nurs Res. 2011;33(8):993-5.

18.Randal C, Pratt D, Bucci S. Mindfulness and self-esteem: a systematic review. Mindfulness. 2015;6(6):1366-78.

19.Pepping CA, O'Donovan A, Davis PJ. The positive effects of mindfulness on self-esteem. J Posit Psychol. 2013;8(5):376-86.

20.Bajaj B, Robins RW, Pande N. Mediating role of self-esteem on the relationship between mindfulness, anxiety, and depression. Pers Individ Differ. 2016;96:127-31.

21.Bishop SR, Lau M, Shapiro S, Carlson L, Anderson ND, Carmody J, et al. Mindfulness: A proposed operational definition. Clinical psychology: Sci Pract. 2004;11(3):230-41.

22.Baer RA. Mindfulness training as a clinical intervention: A conceptual and empirical review. Clin Psychol. 2003;10(2):125-43.

23.Cayoun BA. Mindfulness integrated CBT: Principles and practice: Chichester: Wiley; 2011.

24.Cayoun BA, Francis SE, Kasselis N, \& Skilbeck C. Mindfulness-Based Self Efficacy Scale-Revised (MSES-R). 2012. Retrieved from http://www.mindfulness.net.au/mindfulnessbased-self-efficacy-scale.html

25.Sohrabi A, Sohrabi F. Mindfulness integrated Cognitive Behavior Therapy, with introductory and advanced Audio-instructions of mindfulness training. First edition. Sanandaj; University of Kurdistan Press. 2018; 231-33.

26.Sohrabi A, Fakhraei S, Sohrabi F, Vakili N, Sajadi A, Jalali-zadeh A. Multi side mindfulness and procrastination, evaluating scales and their relationships, with an introductory case study. Proceding in the first national conferences of personality and modern life, Kurdistan, Iran. Azad University of Sanandaj. 2012.

27.Alizadeh T. Evaluating the relationship between self-esteem and source of (externalinternal) with Male and female infertility stress in Tehran [desertation]. Tehran: University of Tarbiat Moalem, Faculty of Psychology and Educational Sciences. 2003.

28.Eskandar Z, Dortaj F, Shekhoeslami A. Effect of mindfulness-based cognitive therapy on self-esteem and social anxiety of students [desertation]. Tehran: University of Alameh Tabatabayi, Faculty of Psychology and Educational Sciences, 2014.

29.Akhbari S, Hossein Sabet F. Relationship between mindfulness with self-esteem and assertiveness in girls students. Proceding in the 2 nd international congress of community improvement in the field of counseltation and Islamic education. Tehran, Iran, 2016.

30.Alipoor S, Zegeibi-ghannad S. Investigation of the Relationship of Mindfulness with Psychological Well-being: The Role of Strategic Engagement Regulation and Self-Esteem. J Posit Psychol. 2017;3(2):1-10.

31.Rostami A, Shariatnia K, Khajehvand Khoshli A. The relationship between self-efficacy and mind fullness with rumination among students of Islamic Azad University, Shahrood Branch. Med Sci. 2015;24(4):254-9.

32.Shahmoradi-Tabatabaee T, Ansari-Shahidi M. Effect of communication skills training on Self- Efficacy bank clerks. Proceding in the The First international congress of culture and psychopathology and nurture. Tehran, Iran, 2017.

33.Spears CA, Hedeker D, Li L, Wu C, Anderson NK, Houchins SC, et al. Mechanisms underlying mindfulness-based addiction treatment versus cognitive-behavioral therapy and usual care for smoking cessation. J Consult Clin Psychol. 2017;85(11):1029. 
34.Yeh GY, Chan CW, Wayne PM, Conboy L. The impact of tai chi exercise on self-efficacy, social support, and empowerment in heart failure: insights from a qualitative sub-study from a randomized controlled trial. PLoS One. 2016;11(5):e0154678.

35.Miller CK, Kristeller JL, Headings A, Nagaraja H. Comparison of a mindful eating intervention to a diabetes self-management intervention among adults with type 2 diabetes: a randomized controlled trial. Health Educ Behav. 2014;41(2):145-54.

36.Goldberg SB, Tucker RP, Greene PA, Davidson RJ, Wampold BE, Kearney DJ, et al. Mindfulness-based interventions for psychiatric disorders: A systematic review and metaanalysis. Clin Psychol Rev. 2018;59:52-60.

37.Langer ÁI, Schmidt C, Mayol R, Díaz M, Lecaros J, Krogh E, et al. The effect of a mindfulness-based intervention in cognitive functions and psychological well-being applied as an early intervention in schizophrenia and high-risk mental state in a Chilean sample: study protocol for a randomized controlled trial. Trials. 2017;18(1):233.

38.Garland EL, Roberts-Lewis A, Tronnier CD, Graves R, Kelley K. Mindfulness-oriented recovery enhancement versus CBT for co-occurring substance dependence, traumatic stress, and psychiatric disorders: proximal outcomes from a pragmatic randomized trial. Behav Res Ther. 2016;77:7-16.

39.Kim SH, Schneider SM, Bevans M, Kravitz L, Mermier C, Qualls C, et al. PTSD symptom reduction with mindfulness-based stretching and deep breathing exercise: a randomized controlled clinical trial of efficacy. J Clin Endocrinol Metab. 2013;98(7):2984-92.

40.Cayoun BA, Francis SE, Shires AG. The clinical handbook of Mindfulness-integrated Cognitive Behavior Therapy: a step-by-step guide for therapists: John Wiley \& Sons; 2018. 